\title{
O PERSONAL TRAINER NA PERSPECTIVA DO MARKETING
}

\author{
MS. CIBELE BIEHL BOSSLE \\ Doutoranda em Ciências do Movimento Humano pelo PPGCMH da EsEF/UFRGS \\ (Rio Grande do Sul - Brasil) \\ e-mail: cibele.bossle@terra.com.br \\ DR. ALEX BRANCO FRAGA \\ Doutor em Educação e Professor do Programa de Pós-Graduação \\ em Ciências do Movimento Humano da ESEF/UFRGS \\ (Rio Grande do Sul - Brasil) \\ e-mail: brancofraga@gmail.com.br
}

\begin{abstract}
RESUMO
Esse estudo apresenta mapeamento das referências dedicadas à formação do personal trainer em bases de dados eletrônicas. Essa garimpagem revelou baixa produção científica sobre o assunto e mostrou que na literatura sobre personal trainer predominam livros com linguagem corrente no mundo dos negócios. Esses achados nos levaram a indagar sobre a força do discurso físico-empresarial, especialmente o marketing, na constituição desta ocupação profissional. Jeremy Rifkin, Zygmunt Bauman, Paula Sibilia e Denise Sant'Anna permitiram visualizar que o marketing dirigido ao personal trainer tem como tarefa reinventar, ressignificar e "repaginar" esta modalidade de serviço em nome da sobrevivência no disputado mercado da vida ativa.
\end{abstract}

PALAVRAS-CHAVE: Personal trainer; marketing; formação profissional; Educação Física. 


\section{INTRODUÇÃO}

Ao observar a sala de musculação de uma grande academia de ginástica se obtém uma visão geral do espaço e das pessoas que o compõem. A movimentação é constante nesta ampla sala repleta de pessoas que vêm e vão, em uma dinâmica ininterrupta. A maioria destas pessoas não está sozinha e movimenta-se em duplas. Duas a duas, as pessoas deslocam-se de aparelho em aparelho de musculação e nunca se separaram. Mais atentamente, percebe-se que somente um integrante da dupla realiza os exercícios, enquanto o outro integrante o observa e o acompanha. Cada executor de exercícios possui o seu respectivo acompanhante, nunca está só neste constante ir e vir.

Este acompanhante é reconhecido nas academias de ginástica e musculação como treinador personalizado' ou personal trainer, que trabalha com treinamento personalizado ou personal training. O personal trainer é definido por Sanches (2006, p. 5 I) como um "profissional formado/graduado em Educação Física que ministra aulas personalizadas, formulando e executando programas de treinamento específicos para cada aluno". Este profissional emergiu como um treinador físico individualizado, pautado pelo discurso da atividade física para a saúde.

Brooks (2008) comenta que nos Estados Unidos da América (EUA) a cobertura dada pela mídia ao treinamento personalizado parece ter atingido seu ápice no início da década de 1980 e que os centros de exercícios físicos em Los Angeles e New York eram apontados em muitos artigos como os locais de proveniência dessa modalidade.

A aderência de atores norte-americanos ao personal training, e a consequente exposição na mídia, contribuiu com a expansão dessa modalidade. Para Domingues Filho (2006) o treinamento personalizado ganhou espaço na mídia mundial quando estrelas de Hollywood e do showbiz adotaram o serviço de instrutores particulares de ginástica por falta de tempo para irem a academias e para evitar o assédio dos fãs. Deliberador (1998) afirma que os resultados obtidos com atrizes como Madonna, Demi Moore e outros, fizeram com que o personal training se tornasse conhecido aos olhos do mundo. $\mathrm{Na}$ esteira do glamour hollywoodiano, os termos da língua inglesa "personal training" e "personal trainer" foram difundidos para outros países, como o Brasil.

I. A tradução mais apropriada de personal trainer para a Língua Portuguesa é treinador pessoal. No entanto, a bibliografia especializada consagrou a expressão "treinador personalizado" para a tradução de personal trainer e "treinamento personalizado" para a de personal training (BARBOSA, 2008; BROOKS, 2004, 2008; DOMINGUES FILHO, 2006; GUEDES JÚNIOR, 1997; GUISELINI, 2007; MONTEIRO, I998; MONTEIRO, 2000; NOVAES; VIANNA, 1998). 
Barbosa (2008) relata a chegada do treinamento personalizado no Brasil em meados dos anos 1980 e que o seu "boom", grifo do autor, ocorreu na década de 1990, em razão dos progressos científicos sobre os benefícios do exercício sistematizado e a divulgação da mídia sobre a importância da atividade física orientada por profissionais. O personal training emergiu como um "novo modismo" (RODRIGUES; CONTURSI, 1998).

Desde então, o treinamento personalizado vem ganhando espaço e aumentando a sua participação no mercado da atividade física. Quando os meios de comunicação de grande circulação destacam a atividade física orientada e individualizada, logo emerge a figura deste escultor da forma física. A televisão, os jornais e as revistas especializadas em fitness reservam sistematicamente espaços para apresentar dicas destes profissionais. O personal trainer está na mídia.

O presente estudo objetivou problematizar a formação do profissional de Educação Física que atua neste ramo de alta visibilidade no cenário contemporâneo e foi produzido a partir da dissertação de mestrado intitulada "Personal Trainer \& Cia": noções de marketing na literatura sobre treinamento personalizado, produzida no Programa de Pós-Graduação em Ciências do Movimento Humano da Escola de Educação Física da Universidade Federal do Rio Grande do Sul, defendida em 2009.

\section{GARIMPAGEM TEXTUAL}

O nosso interesse em problematizar a formação do profissional de Educação Física que atua como personal trainer emergiu durante um levantamento preliminar de literatura realizado para a construção do anteprojeto de mestrado. Esse levantamento foi realizado em bases de dados de bibliotecas de Instituições de Ensino Superior do Rio Grande do Sul ${ }^{2}$ na tentativa de analisar o que estava disponível sobre esse tema em cursos de formação inicial em educação física, já que é a graduação nesta área de conhecimento que habilita para o exercício profissional como treinador personalizado no Brasil.

2. Pontifícia Universidade Católica do Rio Grande do Sul (PUCRS), Universidade Federal do Rio Grande do Sul (UFRGS), Universidade do Vale do Taquari (UNIVATES), Faculdade Cenecista de Osório (FACOS), Universidade Luterana do Brasil (ULBRA) e Universidade do Vale dos Sinos (UNISINOS). $\mathrm{O}$ critério de escolha das instituições foi estabelecido mediante a busca de um relativo equilíbrio entre perfis de representatividade tipológica (MOLINA NETO, 2004).

3. De acordo com a Lei ${ }^{\circ} 9.696$ de $1^{\circ}$ de setembro de 1998 , Art. $3^{\circ}$, compete exclusivamente ao Profissional de Educação Física, coordenar, planejar, programar, supervisionar, dinamizar, dirigir, organizar, avaliar e executar trabalhos, programas, planos e projetos, bem como, prestar serviços de auditoria, consultoria e assessoria, realizar treinamentos especializados, participar de equipes multidisciplinares e elaborar informes técnicos, científicos e pedagógicos, todos nas áreas de atividades físicas e do desporto. Disponível em: < http://mww.confef.org.br/imagens/DO_G.jpg > . Acesso em: 02 jul. 2009 (grifo nosso). 
Um total de dezoito livros ${ }^{4}$ foi localizado nas bibliotecas pesquisadas. $\bigcirc$ teor dessa literatura muito nos surpreendeu, pois esperávamos encontrar algumas informações mais voltadas à atualização em fisiologia e treinamento físico. Porém, a maioria ${ }^{5}$ dos livros disponíveis estava dividida em dois grandes temas: treinamento físico e marketing. $O$ volume de informações sobre noções de marketing despertou nossa atenção, pois não esperávamos encontrar tal "conteúdo", tampouco uma linguagem marcadamente empresarial, na literatura consultada. Palavras como cliente, concorrência, negociação, venda, credibilidade, serviço, propaganda, consumidor, produto e mercado foram usadas de forma recorrente nesses livros.

A maioria dos livros é concebida em formato de manual, pois prescreve detalhadamente cada passo a ser dado em busca do sucesso como personal trainer. Esses livros tipo "auto-ajuda" são endereçados a professores de Educação Física que pretendem trabalhar como treinadores personalizados e contêm orientações sobre estratégias de marketing, marketing pessoal, marketing de adesão, captação de clientes, aspectos contratuais, montagem de programas de treinamento e a preocupação com a crescente concorrência no mercado da atividade física. São exemplos de capítulos que compõem essa bibliografia: "Como me vender com sucesso" (BARBOSA, 2008, p. 5I), "Negócios e assuntos legais" (O'BRIEN, I999, p. I5), "Atrair e manter uma clientela" (BROOKS, 2008, p. I09) e "Marketing aplicado ao personal training" (RODRIGUES, 1996, p. 8).

O modo como o marketing emergiu nesta literatura dirigida ao treinador personalizado nos levou a fazer a seguinte indagação: por que noções de marketing ganham tanta força na literatura voltada ao personal trainer? A partir daí passamos a investigar algo que apenas vislumbrávamos naquele momento: a "marketização" do personal trainer. Tomamos, então, o levantamento preliminar como ponto de partida e, utilizando a metodologia da análise do discurso (FOUCAULT, 1997),

4. Barbosa (2008); Brass (1995); Brooks (2000); Brooks (2004); Brooks (2008); Deliberador (1998); Domingues Filho (2006); Guedes Júnior (1998); Guiselini (2007); Monteiro (1998); Monteiro (2000); Novaes e Vianna (1998); O'Brien (1999); Oliveira (1999); Rodrigues (1996); Rodrigues e Carvalho (1997); Rodrigues e Contursi (1998); Sanches (2006).

5. Para proporcionar um panorama das obras estudadas, bem como, demonstrar a preocupação em não generalizar as informações, os livros foram agrupados do seguinte modo: a) Obras que não utilizam linguagem de cunho empresarial e não fazem qualquer referência ao marketing: Brass (1995), Rodrigues e Carvalho (1997), Brooks (2000); b) Obras que utilizam linguagem de cunho empresarial e/ou fazem referência ao marketing: Monteiro (1998), Novaes e Vianna (1 998), Oliveira (1999), Monteiro (2000), Brooks (2004), Sanches (2006), Guiselini (2007); c) Obras que, além de utilizar linguagem de cunho empresarial, dedicam um ou mais capítulos ao marketing/divulgação/ propaganda: Rodrigues (1996), Guedes Jr. (1997), Rodrigues e Contursi (1998), Deliberador ( 1998), O’Brien (1999), Domingues Filho (2006), Barbosa (2008), Brooks (2008).

6. Bauman (2007). 
investigamos os elementos que permitiram a inserção de noções de marketing na literatura sobre treinamento personalizado.

Para a construção da dissertação da qual extraímos este artigo, expandimos a busca do levantamento preliminar e também analisamos outras bases de dados na tentativa de encontrar mais produções que tratassem da formação do treinador personalizado. Examinamos, então, o Banco de Teses da Coordenação de Aperfeiçoamento de Pessoal de Ensino Superior (CAPES), a Biblioteca Digital de Teses e Dissertações do Instituto Brasileiro de Informação em Ciência e Tecnologia (IBICT), a Biblioteca Virtual em Saúde (BIREME), a Revista Movimento, a Revista Brasileira de Educação Física e Esporte (RBEFE), a Revista Brasileira de Medicina do Esporte (RBME), a Revista Brasileira de Biomecânica (RBB), a Revista Brasileira de Cineantropometria e Desempenho Humano (RBCDH) e a Revista Brasileira de Ciências do Esporte (RBCE').

$\mathrm{Na}$ Revista Movimento analisamos trinta e quatro números que compõem catorze volumes no período compreendido entre 1994 até jan/abr. de 2008. Na RBEFE examinamos dezessete números de quatro volumes do período de jan/mar de 2004 a out/dez. de 2007. Na RBME analisamos o período de jul/ago. de 200 I a set/out. de 2007, em sete volumes compostos por trinta e sete números. Na RBB examinamos dezesseis números de nove volumes, que correspondem ao período de 2000 a 2008. Na RBCDH, analisamos vinte e um números de dez volumes de 1999 até 2008. Na RBCE analisamos as edições de setembro de 2000 até maio de 2008, que compõem oito volumes e vinte e quatro números.

Além dos dezoito livros já citados, encontramos cinco dissertações ${ }^{8}$ de mestrado, sendo que duas apresentam o treinador personalizado como foco central (ALMEIDA, 2005; PINHEIRO, 2000) e as demais somente como tema periférico. Porém não tratam diretamente de formação profissional, pois Almeida (2005) procura identificar em que medida os homossexuais masculinos escolhem seus personal trainers pela estética e Pinheiro (2000) discute o descompasso entre as expectativas dos beneficiários e a dos profissionais do treinamento personalizado.

Além das dissertações, localizamos dez artigos ${ }^{9}$, sendo que somente dois estão diretamente relacionados à formação profissional do personal trainer: Malek et al.

7. A RBCE não estava disponível eletronicamente naquela época, portanto foi analisada de forma manual.

8. Almeida (2005), Garcia (2005), Marotto (1999), Pinheiro (2000), Widhagem (2005).

9. Matiello Júnior e Gonçalves (200 I), Fischer; Bryant (2008), Malek et al. (2002), Dacca; Furlan (2000), Smeltzer; Fewster (2002), Ratamess et al. (2008), Nansel et al. (2007), Nichols et al. (2000), Mazzetti et al. (2000), Bossle (2008). 
(2002) e Bossle (2008). Os artigos de Dacca e Furlan (2000), Mazzetti et al. (2000), Nansel et al. (2007), Fischer e Bryant (2008), Ratamess et al. (2008), Smeltzer e Fewster (2002) e Nichols et al. (2000) fazem referência à eficácia do treinamento personalizado e/ou do acompanhamento realizado pelo personal trainer. Já o artigo de Mattielo Júnior e Gonçalves (200 I, p. I) discute, pautado por princípios éticocientíficos, as "possíveis inconsistências e equívocos assumidos pela hegemonia das elaborações sobre atividade física relacionada à saúde".

A análise do material levantado na busca expandida revelou baixa produção científica relacionada à temática personal trainer e, em especial, à formação desse profissional. A formação do treinador personalizado parece estar apoiada, basicamente, em literaturas como as encontradas durante a busca preliminar nas bases de dados de bibliotecas de Instituições de Ensino Superior do Rio Grande do Sul.

\section{A "SUPER MICROEMPRESA" PERSONAL TRAINER'10}

Para Rifkin (200 I ) estamos mudando da era industrial, centrada na produção, na troca e no acúmulo de bens, para a era do acesso, voltada para a economia da experiência, onde toda a atividade humana passa pela esfera comercial. $\bigcirc$ acesso a ideias, conceitos e imagens ocupa o lugar e a importância que os bens materiais ocupavam na era industrial e representa o valor comercial da nova economia. Os vendedores e compradores de bens estão sendo substituídos por fornecedores e usuários de acesso.

O mercado de trabalho também parece sofrer transformações nessa nova economia. Rifkin (200 I) chama a atenção para o fato de que está ocorrendo uma transformação da perspectiva de produção, que regia a era industrial, para uma perspectiva de marketing que passa a imperar na era do acesso. Nessa nova era a produção passa a ser vista somente como uma função auxiliar de marketing.

A era industrial fazia uso da força de trabalho braçal, da mão-de-obra operária nas fábricas. Na era do acesso, o emprego é um privilégio das "subjetividades equipadas com as qualidades voláteis mais cotadas no mercado de trabalho contemporâneo, tais como criatividade, a inteligência e as habilidades comunicativas" (SIBILIA, 2002, p. 169). Essas qualidades são estabelecidas por um mercado de trabalho instável e volúvel, que exige a habilidade e a preocupação de estar sempre

10. Esta seção foi baseada em uma seção homônima que integra a dissertação de mestrado que lhe precedeu (BOSSLE, 2009). Nesta seção buscamos uma reflexão sobre o discurso contido nos livros localizados sobre a temática personal trainer a partir das formulações de autores como Rifkin (200 I), Bauman (2005, 2007, 2008), Sibilia (2002) e Sant'Anna (200 I). 
visando a atualização através da busca de novas informações. Novas tecnologias de informação e de comunicação parecem ter incrementado o desenvolvimento do marketing a ponto de estar abrangendo toda a experiência humana e de tornar todo indivíduo integrante de um mercado comercial. Bauman (2005, p. 98) aponta que, na lógica desse momento contemporâneo, "todos estamos dentro e no mercado, ao mesmo tempo clientes e mercadorias".

Neste sentido, Rifkin (200 I , p. 92) alerta que "quando praticamente todo o aspecto de nosso ser se torna uma atividade paga, a vida humana em si se torna o melhor produto comercial, e a esfera comercial se torna o árbitro final de nossa existência pessoal e coletiva".

Bauman (2007, p. I I 6) vai ao encontro das ideias de Rifkin ao apontar que a "difusão de padrões de consumo tão amplos a ponto de abraçar todos os aspectos e atividades da vida pode ser um efeito colateral inesperado e não planejado da ubíqua e inoportuna 'marketização' dos processos da vida". Essa "marketização" parece invadir até mesmo áreas da existência humana como as relações interpessoais, oferecendo soluções para os problemas da vida sempre pautadas pelo consumo de mercadorias.

Assim, tudo parece estar enquadrado como mercadoria a ser consumida. Sibilia (2002, p. 172) destaca que "no mundo contemporâneo, a vida passou a ser definida como um produto, como uma mercadoria, uma invenção humana”. Mercadorias, produtos e serviços são imbuídos de valores condizentes com as ideias as quais estão atrelados. Rifkin (200 I , p. 45) pontua que a capacidade de controlar e vender ideias passou a ser entendida como a "expressão mais importante da nova proeza comercial”. As empresas estão deixando de vender produtos para comercializar ideias, os clientes passaram a comprar o acesso a essas ideias e às experiências relacionadas a elas.

Neste sentido, o personal trainer parece estar inserido na lógica da nova era como fornecedor de acesso à experiência de um treinamento individualizado ao seu usuário, ou ainda, de acordo com Rodrigues (1996, p. 12), no papel de uma "super microempresa" que vende serviços de aptidão e visa conquistar e satisfazer o desejo do cliente, a fim de mantê-lo fiel à empresa. Essa "super microempresa" é constituída por uma só pessoa, sem vínculos empregatícios, sem local específico de trabalho que precisa dar conta de sua demanda profissional e se preocupar em demarcar seu território no mercado da atividade física.

Segundo Sibilia (2002, p. 36), "enquanto os cidadãos do mundo globalizado vão incorporando o papel de consumidores, a lógica da empresa passa a permear a totalidade do corpo social, impondo o seu modelo a todas as instituições". Esse modelo empresarial parece ser absorvido pelo personal trainer, que concentra todos 
os setores de uma empresa, sendo ele próprio a empresa' ', uma empresa móvel, leve, sem a solidez de paredes. Rifkin (200I , p. 42) aponta que "o novo mercado do século XXI favorece as empresas 'mais leves', onde o valor é medido em ideias em vez dos pesados ativos tangíveis".

A literatura sobre a temática personal trainer assinala que este profissional é responsável pelo funcionamento integral do seu negócio, pois mantê-lo é algo que deve ser feito por conta e risco do indivíduo-empresa. Neste sentido, O’Brien (1999, p. 10) comenta que "quando você trabalha por conta própria, você tem de ser uma série de profissionais ao mesmo tempo: gerente, contador e secretário, assim como provedor de serviço". Porém, Brooks (2008) chama a atenção para o estresse que demanda exercer papéis demais.

Gerenciar a empresa personal trainer parece envolver diversas habilidades: a identificação do público alvo, a captação de clientes, a venda do seu serviço, a execução da prestação do serviço dirigida ao cliente que foi captado, a retenção e fidelização desse cliente e a fixação da imagem da empresa personal trainer para se manter no mercado competitivo da atividade física.

A literatura ressalta que o marketing é fundamental para a atuação do treinador personalizado frente ao mercado. Várias estratégias de marketing são prescritas com vistas ao êxito nesta fabricação de clientes para a empresa personal trainer, como: estabelecer parcerias (médicos, fisioterapeutas, academias, quiropratas), mandar mensagens de felicitação em datas especiais para os clientes, fazer propaganda em todos os meios de comunicação possíveis e criar seu próprio slogan. Sites promocionais, cartazes, folders, slogans, propagandas em vias públicas e em jornais e revistas de tiragem diversa constituem-se em instrumentos de marketing indicados pela literatura para a promoção do personal trainer.

A preocupação com o desenvolvimento de um relacionamento duradouro com os clientes é também é marcante na literatura analisada. Rifkin (2001, p. 70) comenta que, na lógica da era do acesso, a nova ideia em marketing é concentrarse na participação do cliente e sublinha que "os serviços estão sendo reinventados como relações multifacetadas de longo prazo entre servidores e clientes". Esse autor explica ainda que, no lugar de vender um produto de cada vez ao máximo de clientes possível, a ideia dos especialistas em marketing é estabelecer um relacionamento de longo prazo com cada cliente.

A manutenção de relações de longo prazo, contínuas e permanentes, com o cliente pode ser entendida como um objetivo do treinamento personalizado e

I I. Sanches (2006 p. 52) entende que, para fins jurídicos "o personal trainer não deve ser enquadrado como empresário, mas sim como profissional liberal”. 
se concretiza na ideia de gerenciamento da vida desse cliente. Portanto, a atuação do personal trainer não se restringe somente ao treinamento físico do cliente e seu exato momento de execução, mas à totalidade de seu cotidiano. Inclui, também, a gerência da sua rotina diária, dos seus hábitos alimentares, dos seus horários de sono, do seu vestuário. Assim, "o cliente ganha acesso à experiência especializada e a conselheiros confiáveis que agem em nome dele, muitas vezes como agentes, procuradores ou defensores" (RIFKIN, 200 I, p. 85).

Nesse sentido, o personal trainer poderia ser pensado como um agente de potencialização dos cuidados do corpo do seu cliente, que o encarrega desse extenuante e inacabável trabalho, pois:

Não dar conta de si mesmo, em sociedades nas quais o "si mesmo" tornou um negócio de total responsabilidade de cada um, torna-se um novo fantasma, tão terrível quanto o antigo fantasma das culpabilidades escondidas a sete chaves (SANT'ANNA, 200 I, p. 25).

Este cuidado realizado e negociado pela empresa personal trainer parece estar inserido em um momento histórico onde "o tempo e a atenção se tornam a posse mais valiosa" (RIFKIN, 200 I , p. 9) e a "ansiedade em torno dos cuidados com o corpo uma fonte de lucros potencialmente inexaurível" (BAUMAN, 2007, p. 121 ).

Assim, o gerenciamento de clientes, a escolha de estratégias de marketing, a captação e retenção de clientes e a competição com a concorrência são atribuições desse profissional que emerge sob a ótica de um capitalismo voltado para o consumo.

\section{CONSIDERAÇÕES TRANSITÓRIAS}

As novas tecnologias em comunicação e a velocidade crescente da informação colocaram o marketing em uma posição central no atual "mercado hipercompetitivo" (RIFKIN, 200 I), onde tudo, material ou imaterial, torna-se negociável. Rifkin (200 I) e Bauman $(2005,2007,2008)$ proporcionam o entendimento crítico desse momento histórico onde o marketing está abrangendo toda a experiência humana e tornando todo e qualquer indivíduo integrante de um mercado comercial. Pensar no marketing abarcando todos os processos da vida humana parece ser uma pista para compreender a emergência de noções de marketing na literatura dirigida à formação de treinadores personalizados.

As noções de marketing preconizadas pela literatura analisada têm a finalidade de ampliar a capacidade de comercialização tanto do produto personal training, quanto do profissional personal trainer. Bauman (2008, p. 13) aponta um momento contemporâneo no qual as posições de produto e de promotor estão ocupadas simultaneamente, onde as pessoas "são ao mesmo tempo, os promotores das mercadorias e as mercadorias que promovem". 
A literatura sobre treinamento personalizado poderia ser pensada como "manuais de sobrevivência" para esta modalidade de fitness que emergiu como um modismo e que utiliza o marketing para ganhar fôlego e continuar existindo no "mercado da vida ativa" (FRAGA, 2006). Podemos pensar que o marketing é responsável pela sobrevivência desta modalidade, pois permanecer em um mercado onde "a 'síndrome consumista' destronou a duração, promoveu a transitoriedade e colocou o valor da novidade acima do valor da permanência" (BAUMAN, 2007, p. 83) transformou-se em uma tarefa árdua, que exige constante mudança. Esta mudança não parece ocorrer somente para conquistar novos espaços, mas principalmente para não perder o espaço já adquirido.

Assim, o marketing dirigido ao (e empregado pelo) personal trainer tem como tarefa reinventar, ressignificar e permanentemente "repaginar" essa modalidade de serviço para evitar cair em desuso, numa fuga ininterrupta da temida obsolescência. Poderíamos pensar em personal trainers como "corpos permanentemente ameaçados pela sombra da obsolescência - tanto a do seu software mental como a do seu hardware corporal - e lançados, por isso, no turbilhão do upgrade constante, intimados a maximizarem a sua flexibilidade e a sua capacidade de reciclagem" (SIBILIA, 2002, p. 207). Flexibilidade necessária para modificar-se e adaptar-se às oscilações do mercado de consumo e reciclagem incessante e necessária a cada nova adequação. Um incansável upgrade torna-se indispensável para evitar o descarte, pois "o espectro da pilha de lixo nunca está distante" (BAUMAN, 2005, p. 99).

\section{The Personal Trainer from a Marketing Perspective}

ABSTRACT: This study presents a mapping of theoretical references for the professional education of personal trainers in electronic databases. Besides revealing this subject's low scientific production, literature also demonstrated the personal trainer's reliance on books employing current business-world language. These findings led us to question the business/physical health discourse, specially marketing for the forming of this professional occupation. Jeremy Rifkin, Zygmunt Bauman, Paula Sibilia and Denise Sant'Anna help to understand that marketing targeted to personal trainers has as a task to reinvent, to resignify and "to repaginate" this type of service in name of survival in the competitive market of active life.

KEY WORDS: Personal trainer; marketing; professional education; Physical Education.

\section{El Personal Trainer en la Perspectiva del Marketing}

RESUMEN: Este estudio presenta mapiamiento de referencias dedicadas a formación del personal trainer en bases de datos electrónicas. Este garimpaje reveló baja producción científica sobre el asunto y mostró que en literatura personal trainer predomina lenguaje común al mundo de los negocios. Esas descubiertas llevaron a indagar sobre la fuerza del 
discurso físico-empresarial, especialmente el marketing, en constitución de esta ocupación profesional. Jeremy Rifkin, Zygmunt Bauman, Paula Sibilia y Denise Sant'Anna permitieron visualizar que el marketing dirigido al personal trainer tiene como tarea re-inventar, re-significar y "re-paginar" esta modalidad de servicio en nombre de sobrevivencia en disputado mercado de vida activa.

PALABRAS CLAVE: Personal trainer; marketing; formación profesional; Educación Física.

\section{REFERÊNCIAS}

ALMEIDA, S. C. F. O primado da visualidade: a estética como critério de escolha do personal trainer por alunos homossexuais. 2005. 267 f. Dissertação (Mestrado) - Curso de Mestrado em Educação Física, UGF, Rio de Janeiro, 2005.

BARBOSA, M. Treinamento personalizado: estratégias de sucesso, dicas práticas e experiências do treinamento individualizado. São Paulo: Phorte, 2008.

BAUMAN, Z. Identidade. Rio de Janeiro: Jorge Zahar, 2005.

. Vida líquida. Rio de Janeiro: Jorge Zahar, 2007.

- Vida para consumo: a transformação das pessoas em mercadorias. Rio de Janeiro: Jorge Zahar, 2008.

BOSSLE, C. B. O personal trainer e o cuidado de si: uma perspectiva de mediação profissional. Movimento, Porto Alegre, v. 14, n. I, p. 187-198, janeiro/abril 2008.

. "Personal Trainer \& Cia": noções de marketing na literatura sobre treinamento personalizado. 2009. 92 f. Dissertação (Mestrado) - Escola de Educação Física, UFRGS, Porto Alegre, 2009.

BRASS, D. H. Seu preparador físico personalizado. Rio de Janeiro: Infobook, 1995.

BROOKS, D. S. Manual do Personal Trainer: um guia para o condicionamento físico completo. Porto Alegre: Artmed, 2000.

. Treinamento personalizado: elaboração e montagem de programas. Guarulhos, SP: Phorte, 2004.

. O livro completo do treinamento personalizado. São Paulo: Phorte, 2008.

DACCA, E. R. G. S.; FURLAN, M. M. D. P. Abordagem fisioterápica associada ao sistema de personal trainer no tratamento da hérnia de disco lombar: relato de caso. Arq. Ciências da saúde UNIPAR, Umuarama, v. 4, n. 2, p. 165-168, maio/agosto 2000. Disponível em: < http:// revistas.unipar.br/saude/article/viewFile/l 022/886>. Acesso em: 06 abr. 2008.

DELIBERADOR, A. P. Metodologia do desenvolvimento: personal training. Londrina: Midiograf, 1998. 
DOMINGUES FILHO, L. A. Manual do Personal Trainer Brasileiro. São Paulo: Ícone, 2006.

FISCHER, D.V.; BRYANT, J. Effect of certified personal trainer services on stage of exercise behavior and exercise mediators in female college students. I Am Coll Health, St Joseph, EUA, v. 56, n. 4, p. 369-76, janeiro/fevereiro 2008. Disponível em: < http://pesquisa.bvsalud.org/ regional/resources/mdl- | 83 |6279>. Acesso em: 06 abr. 2008.

FOUCAULT, M. A Arqueologia do Saber. Rio de Janeiro: Forense Universitária, 1997.

FRAGA, A. B. Exercício da informação: governo dos corpos no mercado da vida ativa. Campinas; Autores Associados, 2006.

GARCIA, L. V. A graduação em educação física da UCB no período de 1976 a 2004: análise das matrizes curriculares no contexto da relação educação física e saúde. 2005. I 5 I f. Dissertação (Mestrado) - Curso de Educação Física, UCB, Brasília, 2005.

GUEDES JR, D. P. Personal training na musculação. Rio de Janeiro: Ney Pereira, 1997.

GUISELINI, M. Exercícios aeróbicos: teoria e prática no treinamento personalizado e em grupos. São Paulo: Phorte, 2007.

MALEK, M. H. et al.. Importance of health science education for personal fitness trainers. Los Angeles, EUA, v. 16, n. I, p. 19-24, fevereiro 2002. Disponível em: < http://pesquisa. bvsalud.org/regional/resources/mdl- | | 834 102>. Acesso em: 06 abr. 2008.

MAROTTO, I. O corpo em discussão: ouvindo professores de Educação Física. 1999. 97 f. Dissertação (Mestrado) - Curso de Educação, UFMT, Cuiabá, 1999.

MATIELLOJUNIOR, E.; GONÇALVES, A. Entre a bricolagem e o personal trainer, ou a relação atividade física e saúde nos limites da ética. In: CONGRESSO BRASILEIRO DE CIÊNCIAS DO ESPORTE 12., 200 I , Caxambu. Anais... Caxambu: CBCE, 200 I . (OBS: Este artigo foi consultado em CD ROOM, não há volume e número de páginas)

MAZZETTI, S.A. et al.. The influence of direct supervision of resistance training on strength performance. Med Sci Sports Exerc, Muncie, EUA, v. 32, n. 6, p. II75-84, junho 2000. Disponível em: <http://pesquisa.bvsalud.org/regional/resources/mdl- I0862549>. Acesso em: 06 abr. 2008.

MONTEIRO, A. G. Treinamento Personalizado: uma abordagem didático-metodológica. São Paulo: Phorte, 2000.

MONTEIRO, W. Personal training: manual para avaliação e prescrição de condicionamento físico. Rio de Janeiro: Sprint, 1998.

NANSEL, T. R. et al. Diabetes personal trainer outcomes: short-term and I-year outcomes of a diabetes personal trainer intervention among youth with type I diabetes. Diabetes Care, 
Bethesda, EUA, v. 30, n. 10, p. 247I-7, outubro 2007. Disponível em: <http://pesquisa. bvsalud.org/regional/resources/mdl- 17620445>. Acesso em: 06 abr. 2008.

NICHOLS, J.F. et al.. Impact of a worksite behavioral skills intervention. Am J Health Promot, Califórnia, EUA, v. 14, n. 4, p. 218-21, março/abril 2000. Disponível em: <http://pesquisa. bvsalud.org/regional/resources/mdl- |09|553 I >. Acesso em: 06 abr. 2008.

NOVAES, J. S; VIANNA, J. M. Personal training e condicionamento fisico em academia. Rio de Janeiro: Shape, 1998.

O'BRIEN, T. S. O Manual do Personal Trainer. São Paulo: Manole, 1999.

OLIVEIRA, R. C. Personal Training. São Paulo: Atheneu, 1999.

PINHEIRO, D. R. V. O perfil do personal trainer na perspectiva de um treinamento físico orientado para a estética, saúde e esporte. 2000. 175 f. Dissertação (Mestrado) - Curso de Ciência da Motricidade Humana, UCB, Rio de Janeiro, 2000.

RATAMESS, N. A. et al. Self-selected resistance training intensity in healthy women: the influence of a personal trainer. J Strength Cond Res, New Jersey, EUA, v. 22, n. I , p. I03-I I, janeiro 2008. Disponível em: <http://pesquisa.bvsalud.org/regional/resources/mdl-18296962>. Acesso em: 06 abr. 2008.

RIFKIN, J. A Era do Acesso. São Paulo: Macron Books, 2001.

RODRIGUES, C. E. C. Personal Training. Rio de Janeiro: Sprint, 1996.

RODRIGUES, C. E. C.; CARVALHO, N. Personal training para grupos especiais. Rio de Janeiro: Sprint, 1997. ;_ Manual do Personal Trainer. Rio de Janeiro: Sprint, 1998.

SANCHES, E. W. Responsabilidade civil das academias de ginásticas e do personal trainer. São Paulo: Editora Juarez de Oliveira, 2006.

SANT'ANNA, D. Corpos de passagem: ensaios sobre a subjetividade contemporânea. São Paulo: Estação Liberdade, 2001 .

SIBILIA, P. O homem pós-orgânico: corpo, subjetividade e tecnologias digitais. Rio de Janeiro: Relume Dumará, 2002.

SMELTZER, C. H.; FEWSTER, L. Getting your own personal trainer. Mich Health Hosp, Chicago, EUA, v. 38, n. 2, p. 30, março/abril 2002. Disponível em: < http://pesquisa.bvsalud. org/regional/resources/mdl- I 1968989>. Acesso em: 06 abr. 2008.

WIDHAGEM, G. M. E. S. Representações sociais sobre a saúde dos professores de educação física que atuam em academias do Rio de Janeiro. 2005. 204f. Dissertação (Mestrado) - Curso de Educação Física, UGF, Rio de Janeiro, 2005. 
Recebido: 26 out. 2009

Aprovado: 17 set. 2010

Endereço para correspondência:

Cibele Biehl Bossle

Rua Felizardo, 750 - Jardim Botânico.

Porto Alegre - RS.

CEP: $90690-200$ 